\title{
Stress Evaluation for Segmental Concrete Box Girder Diaphragm
}

\author{
Pei San Alice Lim ${ }^{1}$, Wen Yi Choo ${ }^{1}$, Chuan Fang Ong ${ }^{1}$ and See Hung Lau ${ }^{1 *}$ \\ ${ }^{1}$ Lee Kong Chian Faculty of Engineering and Science, Universiti Tunku Abdul Rahman, Jalan Sungai \\ Long, Bandar Sungai Long, Cheras, 43000 Kajang, Selangor, Malaysia
}

\begin{abstract}
The box girder component is a major breakthrough in the construction field for its effective geometry behavior and high torsional rigidity. However, the analysis and design of the box girder are complex due to its three dimensional behavior i.e. torsion, distortion and bending in longitudinal and transverse direction. In this paper, the use of finite element model in evaluating the stresses behavior for segmental box girder diaphragm under static loading is demonstrated. The analysis is carried out for both permanent and variable actions based on Eurocode. Parametric study is carried out to evaluate the effects of different parameters on the stress behavior for box girder. This study contributes to a better insight of the stress behavior for box girder such that, under service, the stresses developed will not contribute to significance structural cracks that will affect the serviceability of the structure.
\end{abstract}

\section{Introduction}

The design of the concrete box girder has been widely implemented in bridge construction. The reason for its popularity is due to the high bending and torsional stiffness; economical in terms of the material used; better aesthetic appearance; and better utilization of space inside the box girder [1]. In prestressed bridge, serviceability performance is the major concern.

Cracks due to serviceability limit states may be minor and does not imposed serious problem if the crack width is within the allowable limit specified by various codes. Since, the behavior of concrete box girder is complicated due to its three dimensional behavior which involved torsion, distortion and bending in both transverse and longitudinal direction [2]. Cracks could be serious when three dimensional behavior occurred simultaneously.

Stress analysis carried out in the past mainly focused on behavioral study of the box girder that affected by time-dependent effect, temperature effect, traffic loadings, prestressing forces, different cross sections and etc. [3, 4, 13, 5-12]. Increasing the dimensions or reinforcement is the popular solution to tackle for the high stress induced when critical location was identified [4, 14-18]. This research differs from others such that it focused on the possible over-reinforcement problem which will induced higher stress and

\footnotetext{
* Corresponding author: laush@utar.edu.my
} 
lead to crack. This study will act as a reference for more economical and sustainable design in the future.

Previous studies [17, 19] suggested that less congestion in the anchorage zone will provide a better performance and results in lesser cracks. This study extended the idea that will focus on the overall performance of the concrete box girder by providing suggestion on the reinforcement placement after critical area has been identified. Finite element modelling software ANSYS was used in this study to understand the behavior of the concrete box girder.

\section{Literature review}

Various researches has been carried out to identify the affecting factor in controlling cracks formation, deflection, structural stability and so on $[2,5,10,15,20,21]$. Serviceability performance is important to prestressed bridges, and its performance when respond to loadings can be best manifested in the cracks formed. Previous researches identified the factors that affect the formation of cracks are loading conditions, dimensional parameters, imperfect design method, time-dependent and temperature effects $[1,10,11,15,22,23]$. The most significant problem that affect the concrete durability is the corrosion of tendons and reinforcement when crack formed [4]. Cracks developed when the loadings on the structure exceeded its serviceability limit state. However, the behavior of box girder in real life is complicated [6]. Hence, stress analysis for box girder is crucial in understand the actual state of stress.

The study of box girder bridges is complicated due to its three dimensional behavior that involved the effect of torsion and distortional which act on different plane [1-3, 18, 24]. The stresses induced due to the effect of torsion and distortion is shown in Fig. 1 below.

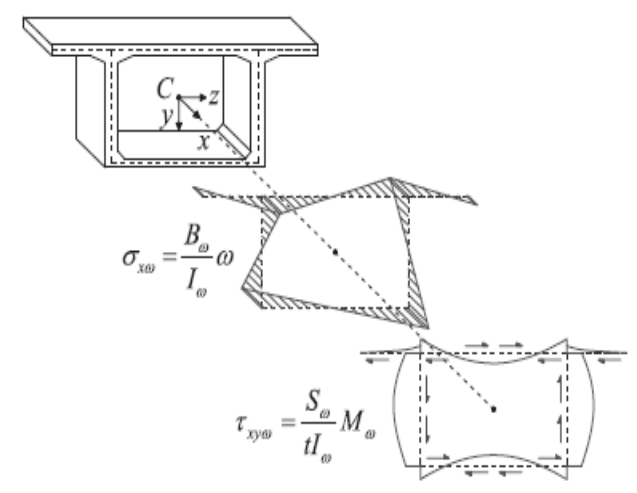

(a)

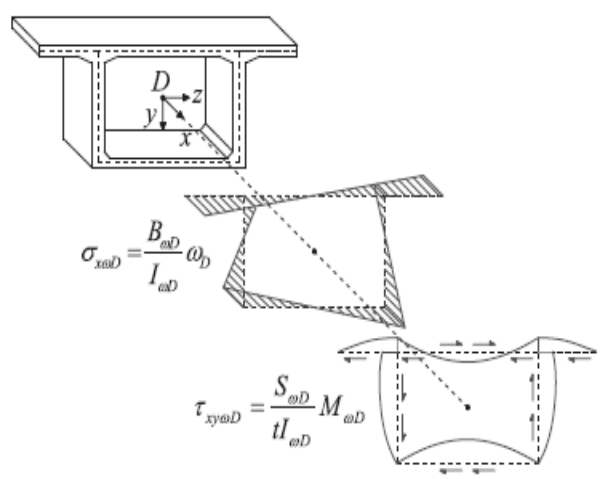

(b)

Fig. 1. Stress State due to (a) Torsional and (b) Distortional Warping [18].

The significance of these effects were carried out by various researchers $[15,18,22-$ 24]. The effect of distortional and warping caused longitudinal stress and transverse bending moment when loaded with eccentric loading. These effects become significant when the structure is not stiff in plane $[22,24]$. Web thickness is the key in controlling the in plane stiffness of the structure [15]. This idea was extended to study the interaction between longitudinal shear and transverse bending [18]. This study highlighted the importance of reinforcement in resisting the magnified tangential stresses due to shear under the effect of torsion and warping. 
Reviews show that increase in dimension and number of reinforcement are the popular industry practice. However, these solutions will result in high construction cost as well as the possibility of over-reinforcement problem. Besides, over-reinforcement in structure will induced high redistribution of reinforcement stress to the concrete. The stress redistribution effect will definitely affect the performance of the structure [17, 25]. Minor cracks formed when the redistribution stress exceeded the effective tensile strength of the concrete [6]. The cracks will impose serious problem to the structure when superimposed with the effects caused by torsion and distortional warping.

\section{Methodology}

This study focused on the double track deck end diaphragm. The shape of the box girder was defined under geometry definition. After the geometry definition, meshing definition would be carried out. Curvature size function method was selected in this study with the minimum element size of $0.02 \mathrm{~m}$, maximum element size of $0.2 \mathrm{~m}$, growth rate of 1.2 and curvature normal angle of 3.14rad. Tetrahedrons element shape was used for complex box girder dimensions. The mesh generated on the box girder is shown in the Fig. 2 below:

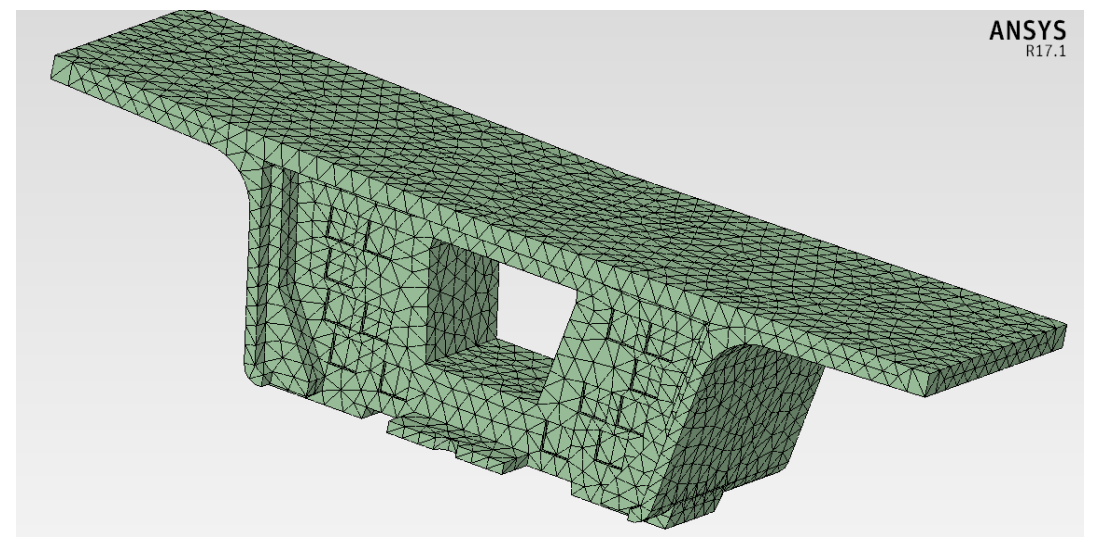

Fig. 2. Mesh Generated.

After mesh was successfully generated, physical properties were defined. Structural physics type was chosen for structural analysis. The whole box girder was selected for the simulation process. After physics region definition, concrete material grade $\mathrm{C} 40 / 50$ was defined with the density of $2500 \mathrm{~kg} / \mathrm{m}^{3}$, Young modulus of $35 \mathrm{GPa}$ and the Poisson ratio of 0.2. Supports and loadings on the structure were defined under structural conditions. Two faces on the box girder were set to be fixed as shown in Fig 3 below: 


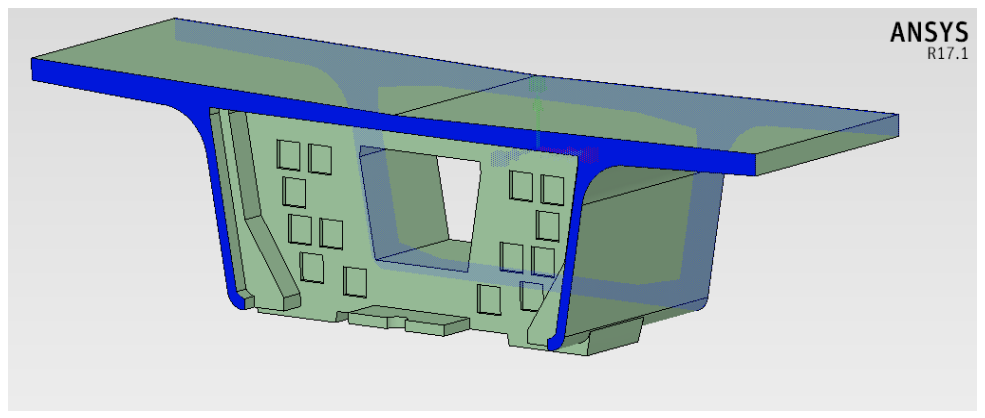

Fig. 3. Supports on Two Faces.

Pressure loadings of $70.76 \mathrm{MPa}$ were applied on 14 faces as shown in the Fig. 4 below:

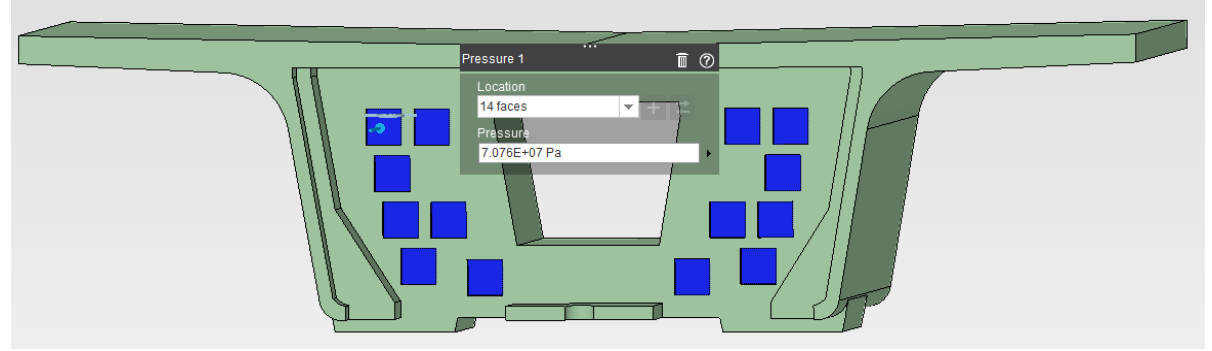

Fig. 4. Pressure Loading on 14 Faces.

Output type during results evaluation was defined under solver option. Equivalent stress, elastic strain and displacement magnitude were selected for this study. Results evaluation is the last step in this study, where all the results will be generated.

Steps involved are summarized as shown in the Fig 5 below: 


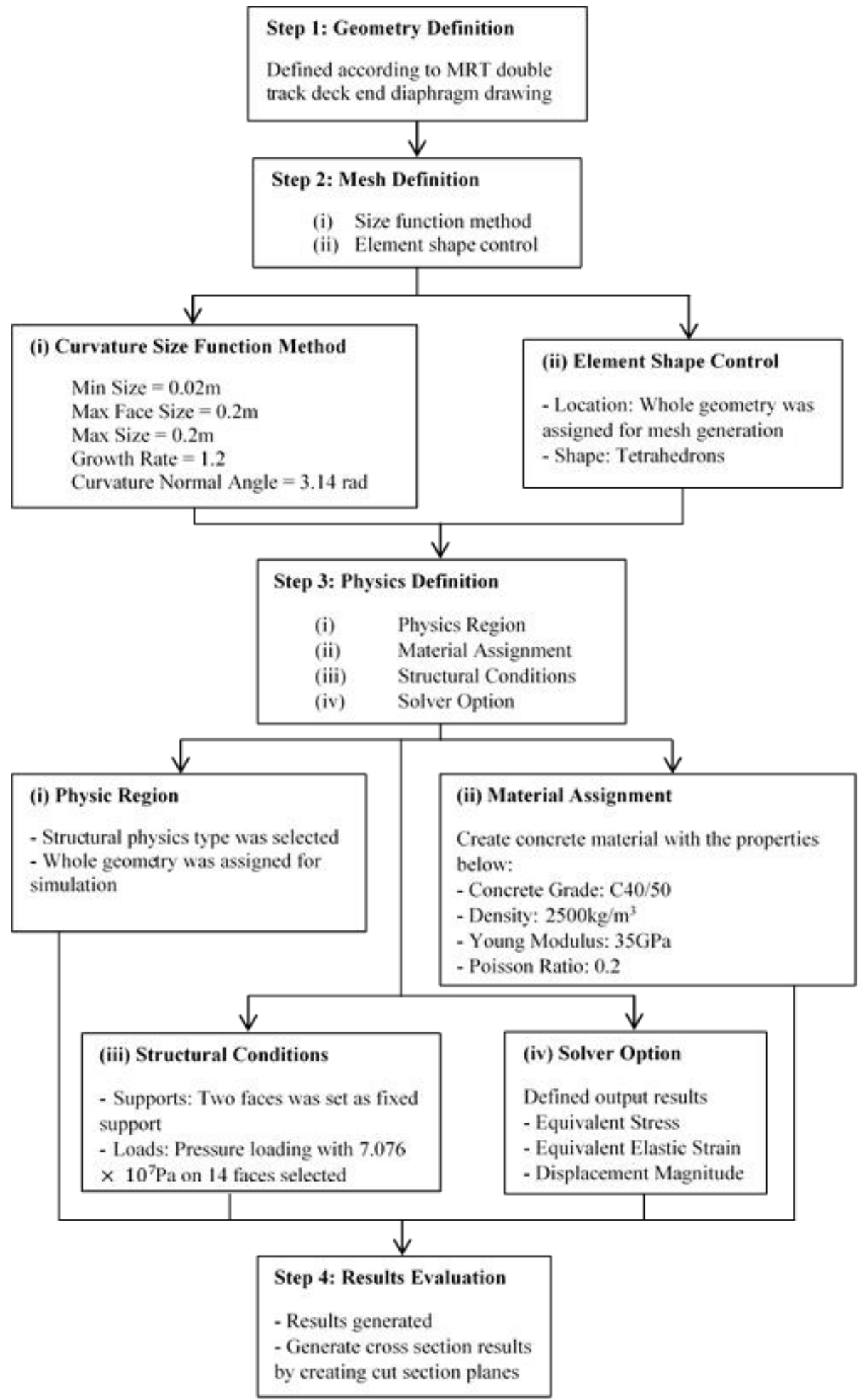

Fig. 5. Summarized Steps for this Study. 


\section{Results and discussion}

Stress analysis for double track deck concrete box girder was carried out using finite element modelling software ANSYS. The respective equivalent stresses of concrete box girder in different locations are shown in Fig. 6 below:

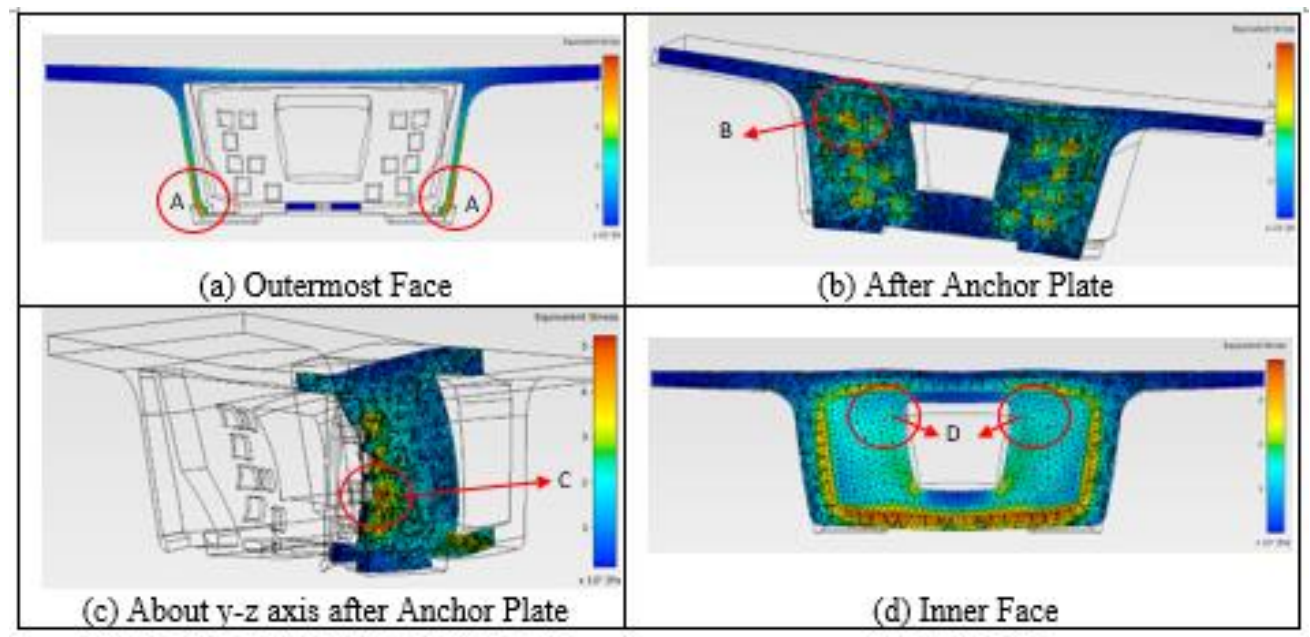

Fig. 6. Equivalent Stress at Respective Locations without Reinforcement.

In this study, it was observed that the highest stress (i.e. $86.567 \mathrm{MPa}$ ) developed at the support surface of the structure area i.e. A as shown in Fig. 6(a). The stress value of 45.789 MPa was observed around the anchor plate as shown in Fig. 6(b). For cross-section in Fig. 6(c), the equivalent stress observed was $52.382 \mathrm{MPa}$ which higher than that from Fig. 6(b). These stresses exceeded the $f_{c k}$ of $40 \mathrm{MPa}$ which would lead to the reduction in the overall stiffness of the structure. Reinforcement is required in these regions to tackle for the stress induced in the concrete. It is important to note that the stress results obtained only represent the concrete alone. Lesser stress is expected to experience by the concrete as reinforcement is involved.

The tensile behavior of the concrete box girder was discussed based on the concrete effective tensile strength. EN 1992-1-1:2004 cl.7.1(2) stated that first crack formed when the flexural tensile stress exceeded the effective tensile strength of the concrete. The effective tensile strength of the concrete, $f_{c t, e f f}$ may refer to mean axial tensile strength of the concrete, $f_{c t m}$ as stated under the same clause $[14,26]$. According to EN 1992-1-1:2004, Table 3.1, the value for $f_{c t m}$ for concrete grade $\mathrm{C} 40 / 50$ as $3.5 \mathrm{MPa}$. When the loading was applied to the box girder, stress recorded near the opening at area $\mathrm{D}$ ranges from $10-$ 20MPa as shown in Fig. 6(d) which exceeded the axial tensile strength of the concrete. Tensile cracks were expected to form at area D. These cracks might not be significant and can be ignored when looking at the minor cracks alone and in the case where torsion and distortion is negligible.

When anchor loads were applied on box girder, restrained faces at the two ends of the box girder caused the cross section to distort as shown in Fig. 7 below. Stress applied caused the section to distort out of plane and hence further induced longitudinal stress namely distortional warping stress on the structure which will lead to complicated behavior for the box girder. The results obtained show the effects due to distortional and warping cannot be neglected and adequate reinforcement is needed to avoid concrete cracking due to these effects. 


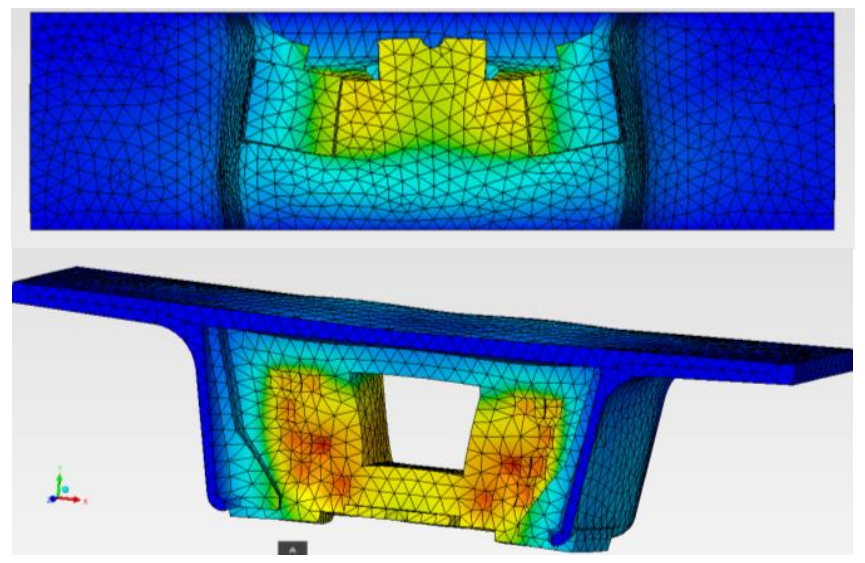

Fig. 7. Distortional Warping Effect in Box Girder from Bottom View (top) and Isometric View (bottom).

Reinforcement is needed at the critical area identified to share the tensile stress that induced on the structure. However, the amount of reinforcement is yet to be justified to avoid over-reinforcement problem. It is important to note that the state of stress will be different when reinforcement is added in the simulation. Hence, it is important to extend the study for reinforced concrete. Analysis must be carried out to justify if the section is balanced reinforced or over-reinforced.

\section{Conclusions}

In conclusion, cracks were expected to form when the stresses on concrete exceeded $60 \%$ of the concrete $f_{c k}$. Cracks formed result in local stresses redistribution in the section which reduced the stiffness of the structure. On the other hand, the present of distortional warping stress in longitudinal direction result from torsion and distortional effect cannot be neglected. When local stresses redistribution effect was superimposed with the induced distortional warping stress, minor cracks that formed will definitely imposed significant serviceability problem.

Conventional solution for these problems is by either increasing the cross-section dimension or adding additional reinforcement. However, extra cage stresses might be induced on concrete due to the bonding between reinforcement and concrete when overreinforced. The extra cage stresses will further complicate the stress behavior of the box girder and brings significant effects to its serviceability performance. Adequate reinforcement must be studied in the concrete box girder for more efficient and economic design.

The authors gratefully acknowledge the financial support from the University Tunku Abdul Rahman Research Funding, UTARRF (IPSR/RMC/UTARRF/2017-C2/L01).

\section{References}

1. Z. Kamaitis and Z. Kamaitis, Statyba, 4, 26-34 (1996)

2. P.K. Gupta, K.K. Singh and A. Mishra, Asian Journal of Civil Engineering (Building and Housing), 11, 135-148 (2010)

3. A.R.M. Fam, Master of Engineering, McGill University Montreal (1969) 
4. A.J. Notkus and Z. Kamaitis, Statyba, 5, 47-52 (1999)

5. M.A. Issa, J Bridge Eng, 4, 116-124 (1999)

6. A. Muttoni and M.F. Ruiz, J Bridge Eng, 12, 646-653 (2007)

7. J. Yim, Y. Cao and M.L. Wang, Proceedings of SPIE - The International Society for Optical Engineering, 7294, 72940 (2009)

8. S.R. Debbarma and S. Saha, Proceedings of the First Middle East conference on monitoring, Assessment and Rehabilitation of Civil Structures, 9 (2011)

9. R. Jain and A. Singh, International Research Journal of Engineering and Technology, 3, 1437-1442 (2016)

10. M.K. Harish, V.R. Chethan and B.T. Ashwini, International Journal for Research Trends and Innovation, 2, 124-128 (2017)

11. H. Huang, S-S. Huang and K. Pilakoutas, J Bridge Eng, 23, 1-15 (2018)

12. H. Yin, Z. Li, X. Hao and B. Zhao, ITM Web of Conferences, 17, 4-12 (2018)

13. T. Reyaz and S.N. Fathima, IRJET, 5, 1912-1919 (2018)

14. CEN Technical Committee, Authority of the Standards Policy and Strategy Committee (2004)

15. X. Wu, J. Li, X. Yi and Z. Zhang, International Conference on Mechanics and Civil Engineering (ICMCE 2014), 953-956 (2014)

16. S.L. Shen, D.W. Hou, J.L. Zhao, S. Horpibulsuk and Z.Y. Yin, Constr Build Mater, 64, 370-378 (2014)

17. A.F. Maree and D.H. Sanders, International Conference on Advances in Experimental Structural Engineering, 64, 1-8 (2015)

18. A. Recupero, M.F. Granata, G. Culotta and M. Arici, J Bridge Eng, 22, 1-17 (2017)

19. A.F. Maree and D.H. Sanders, International Association for Bridge and Structural Engineering, 109, 928-935 (2017)

20. C. Garg and M.V.N.S. Kumar, Int J Civ Eng, 3, 103-112 (2014)

21. N.P. Sasidharan and B. Johny, International Research Journal of Engineering and Technology, 4, 425-429 (2015)

22. M. Arici, M.F. Granata and A. Recupero, International Symposium on Bridge and Structural Engineering, 1-8 (2010)

23. D. Huang and B. Hu, J Bridge Eng, 20, 1-8 (2015)

24. C.H. Yoo, J. Kang and K. Kim, Eng Struct, 87, 70-85 (2015)

25. A.M. Diab, H.E. Elyamany, M.A. Hussein and H.M. Al Ashy, Alexandria Engineering Journal, 53, 355-371 (2014)

26. A.W. Beeby and R.S. Narayanan, Thomas Telford Publishing and Thomas Telford Ltd, London (2009) 